\title{
FAMILY LANGUAGE POLICY, LANGUAGE MAINTENANCE AND LANGUAGE SHIFT: PERSPECTIVES FROM ETHNIC CHINESE SINGLE MOTHERS IN MALAYSIA
}

\author{
Teresa Wai See ONG \\ Griffith University, Australia \\ ongtesa@gmail.com
}

Manuscript received 26 February 2021

Manuscript accepted 21 June 2021

*Corresponding author

https://doi.org/10.33736/ils.3075.2021

\begin{abstract}
Family language policy comprises three components, namely, ideology, practice, and management. Using the conceptual framework of family language policy, this study draws on data from semi-structured interviews and participant observation to explore the role of mothers in the process of language maintenance and language shift in Malaysia. First, it investigates the language choices and ideologies of four Chinese single mothers from Penang that lead to speaking heritage languages and/or dominant languages with their children. Second, it examines the strategies for heritage culture maintenance adopted by these mothers. The study found that two of the mothers speak Chinese heritage languages with their children to reinforce emotional attachment and family cohesion. Conversely, two other mothers face socioeconomic and educational pressures in relation to maintaining Chinese heritage languages, which trigger a shift to using dominant languages such as Mandarin Chinese and English with their children. Nevertheless, all four mothers made efforts in exposing their children to ethnic Chinese cultures. The findings indicate that maintaining heritage languages in the current era has become a challenge for many families in Malaysia while speaking dominant languages is becoming a necessity.
\end{abstract}

Keywords: language maintenance and language shift; family language policy; single mothers; ethnic Chinese; heritage languages; Malaysia 


\section{Introduction}

Language maintenance and language shift is a significant and complex area in sociolinguistic research attracting much attention in recent years. Language shift is broadly understood as the process of replacing one language with another as the medium of communication and socialisation in almost all domains of life by "a speaker, a group of speakers, and/or a speech community" (Pauwels, 2008, p. 719). Consequently, one language is favoured and used often by several generations of speakers. Gradually, the use of the other language(s) diminishes and loses ground. The most dramatic consequence is that the language(s) is completely abandoned by the entire speech community, leading to the phenomenon of language death. In this case, language shift is considered both a process, and an outcome (Pauwels, 2016). Language maintenance is defined as a process whereby a speaker, group of speakers, or speech community decide to continue using their language(s) despite facing competition from the "stronger and more powerful" language(s). The speaker, group of speakers, and/or community usually end up becoming bilingual adapting to the environment of using both their language(s) of the more powerful one(s). Language maintenance is necessary when the use of the speakers' heritage language(s) is reduced to several domains while the more powerful language(s) prevails.

Studies related to language maintenance and language shift have been conducted around the globe (e.g., Brenzinger, 2006; Heinrich, 2004; Walsh, 2005). The situations of language shift examined in these studies range from "a no-longer spoken language to ... an endangered language that still has a high percentage of children speaking it" (Zuckermann, 2020, p. xxi). The reported findings show that many challenges and obstacles emerge, particularly within multilingual societies where the availability of numerous languages creates problems for families in deciding their family language(s). Parents usually face ideological conflicts when choosing the "right" language for their children. They want to maintain their heritage and identity, yet they also want their children to succeed in wider society. At the same time, politics and social media play a role in influencing parental choice. Consequently, tension is created between parental ideologies and concerns, and amid the broader social and cultural contexts. This dilemma is unavoidable, and parents bear responsibility in maintaining a balance for their children between acquiring dominant languages and "sacrificing" heritage languages. Dominant languages in this context refers to language commonly spoken in wider society, while heritage languages is defined as "the language associated with one's cultural background and it may or may not be spoken in the home" (Cho et al., 1997, p. 106).

The present study examines the role of single mothers navigating the process of language maintenance and language shift in Malaysia. The paper begins with a review of literature on family language policy, followed by a discussion of the history of the Chinese community in Malaysia. Accordingly, the aims, research questions, and 
methodological issues are presented. The findings are divided into two sections before ending with some concluding remarks.

\section{Family Language Policy}

The discourse of language policy plays a crucial role in language maintenance and language shift research. This well-researched subject comprises three components, namely, language practices, language ideologies, and language management (Spolsky, $2004,2009)$. The language maintenance and language shift issue are typically framed in various domains such as work, social, religious, and media. However, the family domain remains most vital because it is a space that facilitates free and spontaneous communication between parents, members of the extended family, and children; promotes family cohesion; and protects the integrity of a family system (Pavlenko, 2004; Tannenbaum, 2005). It is within this space that parents are able to witness their children's development of first/heritage language(s), which in turn may lead to the mastery of second and third language(s). All these interactions require detailed analyses of complex emotions, tensions, and conflicts, which are important aspects in providing an in-depth understanding of language maintenance, and language shift.

The above-mentioned actions are usually explored within the framework of family language policy, which is a fast-growing research field in the current era, with bilingualism, and multilingualism becoming the norm. Family language policy is defined as explicit (Shohamy, 2006), and overt (Schiffman, 1996) planning for the language use of family members within the family domain. Specifically, it seeks to clarify what family members do with languages (practices), what they believe about languages (ideologies), and what efforts, and innovations are made to those languages (management) (CurdtChristiansen, 2018). Although research on family language policy focuses on understanding language practices within a family context, it contributes to developing of theories related to children's language acquisition, and language socialisation (De Houwer, 1999). As King and Fogle (2013) have described, "family language policy addresses children language learning and use as functions of parental ideologies, decision-making, and strategies concerning languages and literacies, as well as the broader social and cultural context of family life" (p. 172).

Initially, family language policy research focused on investigating traditional two-parent families in which children learn more than one European language (King, 2016). However, in the present era, diverse family backgrounds - particularly those in transnational and diasporic contexts (e.g., Canagarajah, 2008) -are becoming the norm. In such families, children are socialised in two or more distinct "language communities". Members of these families usually follow language practice norms that are different from the dominant language norms (Lanza, 2007). When one parent speaks a language that is not dominant, children will pick up that language. Subsequently, parents face challenges supporting their children's development of bilingualism, or multilingualism, language use, and school performance while maintaining the social use of heritage 
languages. To understand such diverse family backgrounds' dynamism, it is necessary to analyse and decode parents' language choices, ideologies, and strategies. These, in turn, will reflect parents' language attitudes and personal experiences, which influences and shapes their children's acquisition of heritage, and dominant languages.

With increasing transnational populations in the globalised market, many multilingual families are observed speaking more than three languages (CurdtChristiansen, 2009). Recognising "the diversity of multilingualism within families" (King, 2016, p. 728), there is an increased call for scholars to focus on broader family types, such as adoptive, single-parent, and LGBT families (King, 2016), and study the data from various sociolinguistic angles (Hirsch \& Lee, 2018; Smith-Christmas, 2018). In the case of Malaysia, scholars have conducted many studies that were related to the framework of family language policy. Nevertheless, only one study (Low et al., 2010) has investigated the language use patterns of mothers from various ethnolinguistic groups living in urban Penang. The results support the assertion that mothers' language attitudes play an important part in laying the foundation for their children's heritage language maintenance (Winter \& Pauwels, 2005). Additionally, it aligns with Gal's (1978) comment that young female language users, like mothers, are sensitive towards language change patterns. Nevertheless, the study has limitations in relation to the number of participants, their socioeconomic position, and data not triangulated with other research methods. Therefore, the scholars recommend comparing the findings with data from Chinese community participants in rural parts of Penang, and beyond.

\section{The Chinese Community in Malaysia}

This section provides a brief history of the Chinese community's settlement in Malaysia in relation to language maintenance and language shift issue where many of the present Chinese have shifted from speaking heritage languages to dominant languages. This section is vital for the understanding of the history and current issue since the recruited participants are of ethnic Chinese.

The Chinese are the second largest ethnic group in Malaysia, contributing $22.6 \%$ of the overall population of 32.7 million (Department of Statistics, 2020). Their settlement in the country, which began in Malacca, can be traced back to the 1400s (Andaya \& Andaya, 2017). First established as a strategic trading port, Malacca attracted many merchants, including those from Zhang Zhou in Fujian province, China (Yen, 1993). These Chinese merchants ultimately settled in Malaya (pre-independence name for Malaysia) to continue their business. They married local Malay women and formed the basis of the Peranakan culture in which they spoke a variety of Hokkien that was heavily influenced by Malay also known as Bahasa Melayu.

The late 18th century to the early 20th century witnessed a movement of Chinese immigrants to Malaya for work opportunities (Andaya \& Andaya, 2017). The first wave of settlement that originated in the trading activity in Malacca expanded to Penang. When Sir Francis Light declared Penang as a free-trading port in 1786, it 
attracted traders from China, India, and Southeast Asia. The port provided these traders with opportunities for interactions with European traders, and expanding their commercial activities. The second wave of settlement originated in the gold-mining industry in Sarawak. More Chinese immigrants arrived with additional tin mines opened in the Malayan states of Negeri Sembilan, Perak, and Selangor. The remote location of these tin mines isolated the immigrants, which led to the formation of close bonds for unity. The third wave of settlement was a response to the cash crop industry and development of pepper, and gambier plantations in Johor. The settlement leaders had the power to control the community due to their responsibilities to recruit labourers from China. The labourers formed clan associations, which assisted in accommodation, funeral arrangements, and writing-posting letters back to China.

The Chinese immigrants originated in various provinces in China, mainly Fujian, Guangdong, Hainan, Guangxi, Jiangsu, and Zhejiang (Tan, 2000). Naturally, they spoke a variety of Chinese language (hereafter Chinese heritage languages), e.g., Hokkien, Cantonese, Hainan, Hakka, Teochew, and Fuzhou. The term languages rather than dialects is used because these languages are "not a single language but a family of languages made up of a variety of mutually unintelligible languages" (Bloomfield, 1933, p. 44). As the immigrants married, formed families, and regarded Malaysia as their new home, their children, and grandchildren continued to speak Chinese heritage languages.

Mandarin Chinese is a standardised variety of Beifanghua, which it takes as its phonology, and uses standardised Chinese characters as its orthography (Grey, 2019). In the People's Republic of China, Mandarin Chinese is known as Putonghua (translated as common language), the national language of the country (Chen, 1999). Initially, the Chinese-medium schools imported textbooks from China, but they were replaced after 1952 with locally produced textbooks to reflect Malaysia's lifestyle, and culture. After the country's independence in 1957, Malaysia's education system experienced several episodes of reformations, including the implementation of education and language policies. As a result, Chinese-medium schools were classified as "national-type" schools, which permitted the continuous use of Mandarin Chinese as the language of instruction alongside Bahasa Melayu, and English (Wong, 2017). The Chinese-medium schools were given little attention because the Malaysian government was keen on promoting its national identity by using the sole official language, Bahasa Melayu. Nevertheless, it was reported that more than $90 \%$ of ethnic Chinese parents had sent their children to Chinese-medium schools (Gill, 2014). Moreover, the enrolment rate of non-Chinese students has increased in recent years $(15.33 \%$ for the Bumiputras and $2.75 \%$ for the Indians) (BizTech.Asia, 2020).

As Mandarin Chinese becomes popular and common among the Chinese community in Malaysia today, different aspects of language maintenance and language shift (e.g., language choices, language proficiency, language attitudes) have been examined. The existing studies such as Carstens (2018), and Ting (2018), reveal that a gradual shift away from Chinese heritage languages has occurred in the Chinese households. Parents send their children to Chinese-medium schools because they 
perceive Chinese-medium education as an integral part of preserving Chinese heritage, language, and culture in a Malay-dominant country (Lee, 2012). The Chinese-medium schools that function solely in Mandarin are mainly responsible for the language shift. To an extent, they were found to have switched to Mandarin Chinese, and English when communicating with their children, while Chinese heritage languages were mainly reserved for social communication with friends, and neighbours (Low et al., 2010). Today, the youngest generation in most Chinese families communicates primarily through Mandarin Chinese, and considers Chinese Mandarin as a marker of their ethnic identity. Increasingly, Mandarin Chinese is becoming the family language of many Chinese families in Malaysia.

\section{The Study}

The present study builds on the body of work in family language policy. The first part investigates four ethnic Chinese single mothers from Penang in making their language choices, and ideological position when speaking heritage, or dominant languages with their children. The second part examines the mothers' strategies for heritage culture maintenance. The modus operandi of the investigation is as follows:

1. Which languages do mothers speak to their children, dominant or heritage?

2. What are the reasons for their choice?

3. What strategies do mothers take to maintain their heritage culture?

\section{Methodological Issues}

This project recruited four single mothers, aged 30 to 40 from Penang, through snowball sampling. One of the mothers lived in a rural area, while the other three lived in urban areas. All four subjects were working mothers. Regarding their education level, the rural subject completed secondary school while the urban subjects graduated from university.

According to Arksey and Knight (1999), and Patton (2002), interviews are a valuable resource for a researcher to explore, and obtain in-depth understanding of an issue understudied. Through the interviews the thinking behind the participants becomes apparent, thus the researcher may uncover things that cannot be observed directly. This study used semi-structured interviews as the primary data, and participant observation as the secondary data for triangulation. O'Connor (2006) describes participant observation as "the process of immersing yourself in the study of people you're not too different from"(p. 5). Despite that the researcher was not physically involved with the mothers in their daily lives, participant observation could allow her to become a "convert" (O'Connor, 2006, p. 5), and engage with them to fully understand the phenomenon (Bruyn, 1966).

Upon meeting the four mothers individually, the researcher introduced her study, before briefed them on the process of interviewing, and recording. After becoming 
satisfied with the procedures, the mothers signed a consent form. The interview was conducted using specific guidelines. While the three mothers from the urban area spoke in English the mother from the rural area spoke in a hybrid repertoire consisting of Hokkien, and Mandarin Chinese. Translanguaging took place between the mother, and the multilingual researcher, because they had engaged in "complex and fluid discursive practices" to "make sense" of the interview and "communicate ... appropriate subject knowledge" (García \& Li, 2014, p. 12). Each interview took place at the participant's home for approximately 40 minutes. Subsequently, an hour was spent observing the participant's interactions with her children. Once the observation had been completed, the interviews were transcribed with only minor morpho-syntax corrections for intelligibility sake. All participants' names were removed, and they were identified by double alphabets to maintain confidentiality. Table 1 outlines the basic information of the four participants in this study.

Table 1

Participants' Brief Profile

\begin{tabular}{|c|c|c|c|c|c|}
\hline Mother & Age & $\begin{array}{l}\text { Number } \\
\text { of } \\
\text { children }\end{array}$ & $\begin{array}{l}\text { Gender of } \\
\text { children }\end{array}$ & $\begin{array}{l}\text { Ethnolinguistic } \\
\text { group }\end{array}$ & Heritage language(s) \\
\hline EM & 32 & 2 & Sons & Hakka & Hakka, Hokkien \\
\hline$S Z$ & 30 & 1 & Son & Cantonese & Cantonese, Hokkien \\
\hline DY & 33 & 1 & Daughter & Teochew & Teochew \\
\hline BR & 40 & 2 & Daughter, Son & Hainanese & Hainanese \\
\hline
\end{tabular}

The transcripts were analysed using two approaches, namely, content analysis, and thematic analysis. As "a systematic coding and categorising approach" (Grbich, 2013 , p. 190), content analysis could assist the researcher to explore a large amount of data following explicit rules to determine trends and patterns. Thematic analysis could be a method for analysing patterns within the data (Braun \& Clarke, 2006), and interpreting aspects of the issue understudied (Boyatzis, 1998). First, the key phrases related to the aim of the study were highlighted to produce descriptive codes. These codes were classified into various categories to identify major themes. The themes, divided into three distinctive areas, were used for discussing the findings. 


\section{Findings}

The first section presents findings on the language ideologies of the four mothers in relation to their choices of speaking either heritage languages (SZ and BR), or dominant languages (DY) with their children. The second section discusses the mothers' strategies for cultural maintenance (BR, SZ, EM, and DY). In the findings, it is evident that the mothers' language choices, and ideologies are impacting their children's language acquisition, and development of culture, which indirectly are influencing their family language policy.

\section{Language Choices and Ideologies Related to Speaking Heritage Languages}

When growing up in a multilingual environment, children may face conflicts, as parents expect them to succeed in assimilating into the dominant language environment while maintaining their sense of belonging and identity. In countering such conflicts, children may become disengaged from their ethnic roots leading to estrangement of relationship with the family members. Parents may feel that they are not qualified to teach their children things that parents usually teach, namely, transmitting the heritage languages spoken by family members, and the cultural values and beliefs that the family members consider important (Wong-Filmore, 1991). The increasing conflicts of speech divergence during communication reflects the widening identity gap between parents and children (Gudykunst \& Lee, 2001).

Global languages, particularly Mandarin Chinese has become the dominant language within the Chinese community in Malaysia (Albury, 2017). To attenuate the communication gaps and conflicts, two mothers have made efforts to communicate with their children using Chinese heritage languages. The first subject, SZ, stated that:

To maintain Chinese heritage languages, I think you need to start from small kids. Just like my boy. Actually, it's very important. I speak a mix of Hokkien and Cantonese [to my boy]. It is a must to pass on our languages to the next generation.

Like many mothers, SZ was born and grew up in Penang. Her parents spoke to her in two Chinese heritage languages, namely, Cantonese, and Hokkien. Subsequently, she continued to speak both heritage languages to her son. During the interview, SZ emphasised the importance of speaking heritage languages because she wanted her son to know his family roots. Being able to speak those languages would mean a lot to her son as he grows up. She did not want the family heritage to disappear nor being responsible for causing such disappearance in the future. In SZ's case, her emotional attachment to heritage languages has shaped her language attitude towards her son's language choice - a pattern consistent with the findings from several other studies (e.g., Portes \& Hao, 2002; Sakamato, 2001; Tannenbaum \& Howie, 2002). Noteworthy, SZ's 
heritage language preference aligns with Ong's (2020) observation that "knowing family roots, such as surnames, language groups, and origin of ancestors, is essential in Chinese society and will prevent the family umbilical cord from breaking" (p. 2).

According to Schumann (1978), Portes and Rumbaut (2001), among others, second-language acquisition is a complex issue, often influenced by sociocultural, and economic factors. In Penang, school children learn two to three dominant languages simultaneously. Chinese heritage languages are usually placed below those languages because gaining a high proficiency level in those dominant languages is very important for attaining academic success. However, BR is keen to pass on her heritage language, Hainanese, to her children. Hainanese is central to communication in her home, especially with her mother and sisters. One of the subjects, BR, explained further that:

I speak Hainanese. Within my family, we use Hainanese, our heritage language. I make sure I teach my children. Both can speak the language very well. Most of my uncles from my mum's side and dad's side and their children can't speak the language anymore.

This response indicates that $B R$ is satisfied with the result of her children acquiring a high level of proficiency in Hainanese, which was unlike her uncles' children who could not speak the language. Deducible further is that the heritage language in her uncle's home is not in use unless her uncle decides to revive the language. Although Chinese heritage languages have limited areas of usage and have survived through spoken rather than written (Vollmann \& Soon, 2018) - which hinders many from acquiring them - BR's children have the communication ability to conduct frequent interactions with their grandmother, aunts, and uncles. This may be attributable to the rationale for maintaining family cohesion (Schwartz \& Verschik, 2013), unlike many modern families today where the younger generation cannot communicate with their elders due to the lack of heritage language command. As Fishman (1972) and Spolsky (2004, 2009) point out, the family domain remains important for intergenerational transmission of heritage languages.

\section{Language Choices and Ideologies Related to Speaking Dominant Languages}

As an economic asset, language is used for networking, conducting businesses, and bringing material wealth or financial return. In the current era of globalisation, modernisation, and internationalisation, many job opportunities require people to be mobile, and transnational. The family domain usually determines the language(s) that the children acquire in which parents play a vital role. Many parents, who are keen to optimise their children's future, choose to speak the dominant languages with their children from a young age. The parents usually believe that global communication requires proficiency and fluency to ensure better career prospects, leading to a higher living standard. 
In the case of the Chinese community in Penang, English, and Mandarin Chinese are usually used for networking among young people because these languages are considered as their mother tongues (Albury, 2020). Two of the participants in this study choose to speak dominant languages to their children. One of the single mothers, DY, explained the situation as follows:

The world is very modernised and globalised now, so some people might think of moving to English and Mandarin Chinese rather than heritage languages. Particularly I would say it's a must to know English. If you want to go overseas, you want to have a better life, the lingua franca is English. Mandarin Chinese is spoken for communication purposes. For a Chinese who can understand Mandarin Chinese, it will be easy for him to communicate with others. This is the benefit of Mandarin Chinese. For me, I ensure that my daughter can speak both languages. If she does not learn them, she will lose out.

As a parent, DY considered that both dominant languages are equally important for the current world, and she separated the advantages of learning both languages. She pointed out that English is perceived as the language of educational and professional success, thus speaking English is vital, especially if one intends to travel abroad. As Chan (2019) notes, English no longer belongs solely to native speakers, instead, it belongs to non-native speakers who "learn or use it for a wide range of purposes in diverse social contexts" (p. 105). In the last decade, there has been an overwhelming majority of speakers of English classified under Kachru's (1992) outer, and expanding circles learning and choosing to communicate in English (Chan, 2019).

As for Mandarin Chinese, it is functioning as the working language for adults, students, and professionals of different Chinese ethnicities in Malaysia. That is, Mandarin Chinese is becoming a necessary economic tool, similar to the situation in Singapore, and China (Albury, 2017). When such situation happens, for which the process is known as Mandarinisation, heritage languages are progressively "destroyed" (Goh, 2017). Nevertheless, the process of Mandarinisation allows for cultural transmission, and claiming of a shared Chinese heritage ownership through a common language of Mandarin Chinese (Wong \& Tan, 2017). Therefore, in order not to lose out in the "competition", DY has exposed her daughter to English, and Mandarin Chinese by interchanging both languages when speaking with her. 


\section{Strategies for Heritage Culture Maintenance}

The discussion in the previous sections demonstrates that heritage, and dominant languages hold distinct roles for the four mothers. The maintenance of Chinese heritage languages symbolises family roots, and ethnic origins, while being fluent in English, and Mandarin empowers one to advanced educational, and professional opportunities. Despite the mothers hold different language ideologies due to various pragmatic factors, sociocultural and emotional reasons remain a driving force for the mothers' positive attitudes towards the bilingualism, or multilingualism, and cultural development of their children. Such attitudes are observable in the strategies taken by the mothers understudied.

In addition to speaking Hainanese to her children, the single mother BR practises the traditional way of naming her children, which specifies personal names that are pronounced according to the Hainanese culture:

If you notice the Chinese [in China], their Chinese name is not pronounced according to their heritage language. They change it to Hanyu Pinyin and not maintain it according to their heritage language intonation. I don't put pinyin for my children's name; it doesn't show anything. My children have Hainanese names. I told them that I followed the Hainanese intonations and pronunciations. It's getting less and less of this trend. It reflects how many Chinese in Malaysia still preserve their heritage languages.

The explanation details a traditional way of BR naming the children that reflects the family's ethnolinguistic group identity. As a mother, BR notes that many young parents today no longer follow this tradition because they prefer to give their children modern names, or those written and pronounced according to Mandarin Chinese pinyin. If this dilemma persists, the Chinese community in Penang specifically and Malaysia generally will lose their unique identity.

Conversely, although EM lives in Balik Pulau, a rural area in Penang, she is keen to expose her children to dominant languages. This is partly because she does not earn much, and she hopes her children will be able to advance their socioeconomic mobility, and subsequently achieve a better standard of living in the future. EM speaks Mandarin Chinese to her children at home, while her mother uses Hakka due to a lack of command of Mandarin Chinese. At the school that her children attend, they are exposed to Hakka culture through the school's collaboration with a Hakka clan association:

My children's school has cooperated with the Hakka society for two years, by means of organising cultural activities on Hakka tradition. The activities are not conducted during school hours but after school hours like Saturday, and Sunday. For me, although I am keen about them learning English and Mandarin Chinese, I must keep my Chinese tradition. Like celebrate Chinese 
New Year, the Hakkas have their own style. They also have colouring contest. When they give out leaflets, my children will join.

Hakka cultural activities were organised in EM's children's school to ensure that the younger generation knows and understands Hakka language and culture. As demonstrated in EM's extract, her children's participation in Hakka cultural activities is a form of maintaining the Hakka tradition. The activities highlight the relationship between language, identity, and culture. EM's positive attitude towards her children's exposure to Hakka culture indicates that heritage languages hold a distinctive role in EM's life, which is now passed on to her children.

Although SZ choose to speak a combination of Hokkien and Cantonese with her son, she finds ways to expose him to her heritage culture. Using a "cheap" method, as SZ explained the strategy as follows:

On weekends, he [my boy] follows me to watch Cantonese movies from Hong Kong. They are interesting and there're more storylines and feelings. Many people learn their Cantonese through watching them. They are exciting, the story is challenging and completely different from [the] Mandarin Chinese ones. They even use many proverbs and expressions where he [my boy] can learn Cantonese from them. Sometimes, I feel that certain expressions can only be expressed meaningfully through Cantonese.

The extract above suggests that entertainment programme is a useful form for maintaining heritage language and culture. By watching Cantonese movies, SZ's son is able to learn Cantonese including the proverbs and expressions used in the programme. As a heritage speaker, SZ feels that the meaning of certain expressions can only be delivered appropriately in Cantonese, which makes her heritage language unique. Indeed, SZ has strong emotional attachment to the language due to her heritage history.

Similar to the practice of SZ, the subject DY sent her daughter to a Teochew opera workshop to learn about Teochew culture. The single mother, DY, explained the arts experience as follows:

I feel that Teochew opera is a historical and traditional culture. There is a Teochew opera museum in town and [it] has workshops to teach the opera. The number of people who attended was quite a lot. I sent my daughter there to learn. If there is no such museum, our next generation will not be able to see all this in the future. That is why I hope I can continue to pass the Teochew culture to my daughter. She does not understand much but she enjoys the workshop. I think besides understanding the art of Teochew opera, we can still appreciate it from different perspectives and the feelings in it. 
As a culturally-inclined mother, DY stresses the importance of appreciating the art of performance for cultivating an interest in historical culture among the younger generation, like her daughter. Her comments demonstrate that she supported Teochew opera museum, and the workshops held to celebrate the cultural values of Teochew opera. All three descriptions above shed light on the fact that maintaining a language involves maintaining its culture given the close connection between the two.

\section{Conclusion}

Through the analysis of the interview transcripts, the present study has shed light on the fact that maintaining heritage languages is becoming a challenge within the Chinese community in Malaysia, while speaking dominant languages is turning into a necessity. As evidenced in the findings, two of the mothers chose to speak heritage languages to their children due to strong emotional attachment, personal childhood experience, and ethnolinguistic group identity. Contrastingly, two other mothers felt that speaking dominant languages is more important in the current globalised era because economic security and future prospects depend on proficiency and fluency in those languages (Bordieu, 1991). Such findings are not surprising because many ethnic communities around the globe are facing similar tension and conflict within their family language policy. In fact, the shift to speaking dominant languages, which results in "a remodelling of the sociolectal situation" (Vollmann \& Soon, 2018, p. 103), is perceived as the norm, especially due to competing pressures that derive from the overarching conceptualisations of globalisation. Therefore, addressing this issue is significant to our understanding of how language maintenance and language shift takes place under conditions of rapid sociocultural and political influences. Despite the mothers having different language ideologies, they showed positive attitudes towards strategies for heritage culture maintenance. One of the mothers continued practising the traditional way of naming her children, one other used the entertainment as a channel for heritage language transmission, and two others sent their children to cultural classes. All in all, they felt that maintaining their cultural identity is crucial, and hope that their cultural identity would remain despite the language maintenance challenges. Hence, this issue calls for further research because the nexus between language and identity among ethnic Chinese mothers in Malaysia has not been comprehensively examined in the exploratory study above. It would also be worth looking at other factors related to mothers' attitudes towards heritage language and cultural maintenance and how they impact children's heritage language development. 


\section{Acknowledgement}

The author would like to thank the two anonymous reviewers for their comments on the earlier draft. The data collection was supported by the Griffith University International Postgraduate Research Scholarship (GUIPRS) and the Griffith University Postgraduate Research Scholarship (GUPRS) under project number GU 2016/409.

\section{References}

Albury, N. J. (2017). Mother tongues and languaging in Malaysia: Critical linguistics under critical examination. Language in Society, 46, 567-589.

Albury, N. J. (2020). Language policy, ideological clarification and theory of mind. Language Policy, 20, 193-214.

Andaya, B. W., \& Andaya, L. Y. (2017). A history of Malaysia (3rd ed.). Red Globe Press.

Arskey, H., \& Knight, P. T. (1999). Interviewing for social scientists: An introductory resource with examples. Sage.

BizTech.Asia. (2020). More non-Chinese children enrol in Chinese schools. https://biztech.asia/2020/11/11/more-non-chinese-children-enroll-in-chineseschools/

Bloomfield, L. (1933). Language. Henry Holt.

Bourdieu, P. (1991). Language and symbolic power. Polity Press.

Boyatzis, R. E. (1998). Transforming qualitative information. Sage.

Braun, V., \& Clarke, V. (2006). Using thematic analysis in psychology. Qualitative Research in Psychology, 3(2), 77-101.

Brenzinger, M. (2006). Conceptual loss in space and time: Vanishing concepts in Khwe, a hunter-gatherers' language. Ajia Afurika Gengo Bunka Kenkyujo Tsushin, 116, 7173.

Bruyn, S. (1966). The human perspective in sociology: The methodology of participant observation. Prentice-Hall.

Canagarajah, A. S. (2008). Language shift and the family: Questions from the Sri Lankan Tamil diaspora. Journal of Sociolinguistics, 12(2), 143-176.

Carstens, S. (2018). Multilingual Chinese Malaysians: The global dimensions of language choice. Grazer Linguistische Studien, 89, 7-34.

Chan, J. (2019). Contextualizing teaching English as a local/global language: A bottom-up sociolinguistic investigation. In F. Fang \& H. P. Widodo (Eds.), Critical perspectives on global Englishes in Asia: Language policy, curriculum, pedagogy and assessment (pp. 104-122). Multilingual Matters.

Chen, P. (1999). Modern Chinese: History and sociolinguistics. Cambridge University Press.

Cho, G., Cho, K. S. \& Tse, L. (1997). Why ethnic minorities want to develop their heritage language: The case of Korean-Americans. Language, Culture and Curriculum, 10(2), 106-112. 
Curdt-Christiansen, X. L. (2009). Invisible and visible language planning: Ideological factors in the family language policy of Chinese immigrant families in Quebec. Language Policy, 8, 351-375.

Curdt-Christiansen, X. L. (2018). Family language policy. In J. W. Tollefson \& M. PérezMilans (Eds.), The Oxford handbook of language policy and planning (pp. 420441). Oxford University Press.

De Houwer, A. (1999). Environmental factors in early bilingual development: The role of parental beliefs and attitudes. In G. Extra \& L. Verhoeven (Eds.), Bilingualism and migration (pp. 75-96). Mouton de Gruyter.

Department of Statistics Malaysia. (2020). Current population estimates, Malaysia, 2020.

Fishman, J. A. (1972). Language maintenance and language shift as a field of inquiry: Revisited (1968). In A. S. Dil (Ed.), Language in sociocultural change: Essays by Joshua A. Fishman (pp. 76-134). Stanford University Press.

Gal, S. (1978). Peasant men can't get wives: Language change and sex roles in a bilingual community. Language in Society, 7, 1-16.

García, O., \& Li, W. (2014). Translanguaging: Language, bilingualism and education. Palgrave Macmillan.

Gill, S. K. (2014). Language policy challenges in multi-ethnic Malaysia. Springer.

Goh, Y. S. (2017). Teaching Chinese as an international language: A Singapore perspective. Cambridge University Press.

Grbich, C. (2013). Qualitative data analysis: An introduction. Sage.

Grey, A. (2019). A polity study of minority language management in China focusing on Zhuang. Current Issues in Language Planning, 20(5), 443-502.

Gudykunst, W. B., \& Lee, C. M. (2001). An agenda for studying ethnicity and family communication. Journal of Family Communication, 1, 75-85.

Heinrich, P. (2004). Language planning and language ideology in the Ryūkyū Islands. Language Policy, 3(2), 153-179.

Hirsch, T., \& Lee, J. S. (2018). Understanding the complexities of transnational family language policy. Journal of Multilingual and Multicultural Development, 39(10), 882-894.

Kachru, B. B. (1992). The other tongue: English across cultures (2nd ed.). University of Illinois Press.

King, K. A. (2016). Language policy, multilingual encounters, and transnational families. Journal of Multilingual and Multicultural Development, 37(7), 726-733.

King, K. A., \& Fogle, L. W. (2013). Family language policy and bilingual parenting. Language Teaching, 46(2), 172-194.

Lanza, E. (2007). Multilingualism and the family. In P. Auer \& W. Li (Eds.), Handbook of multilingualism and multilingual communication (pp. 45-67). De Gruyter.

Lee, H. G. (2012). Education of the Chinese in Malaysia. In H. G. Lee \& L. Suryadinata (Eds.), Malaysian Chinese: Recent developments and prospects (pp. 166-192). Institute of Southeast Asian Studies. 
Low, H. M., Nicholas, H., \& Wales, R. (2010). A sociolinguistic profile of 100 mothers from middle to upper-middle socio-economic backgrounds in Penang-Chinese community: What languages do they speak at home with their children? Journal of Multilingual and Multicultural Development, 31(6), 569-584.

O'Connor, T. (2006). Qualitative social science research methodology. North Carolina Wesleyan College Course Syllabus.

Ong, T. W. S. (2020). Why bother maintaining languages? A discussion based on diminishing Chinese dialects in Malaysia. Apples - Journal of Applied Language Studies, 14(1), 1-5.

Patton, M Q. (2002). Qualitative research and evaluation methods (3rd ed.). Sage.

Pauwels, A. (2008). Language maintenance. In A. Davies \& C. Elder (Eds.), The handbook of applied linguistics (pp. 719-737). Blackwell.

Pauwels, A. (2016). Language maintenance and shift. Cambridge University Press.

Pavlenko, A. (2004). 'Stop doing that, la Komu Skazala!': Language choice and emotions in parent-child communication. Journal of Multilingual and Multicultural Development, 25, 179-203.

Portes, A., \& Hao, L. (2002). The price of uniformity: Language, family and personality adjustment in the immigrant second generation. Ethnic and Racial Studies, 25, 889-912.

Portes, A., \& Rumbaut, R. G. (2001). Legacies: The story of the immigrant second generation. University of California Press.

Sakamoto, M. (2001). Exploring societal support for L1 learning and L1 maintenance: A socio-cultural perspective. Australian Review of Applied Linguistics, 24, 43-60.

Schiffman, H. (1996). Linguistic culture and language policy. Routledge.

Schumann, J. H. (1978). The acculturation model for second-language acquisition. In R. C. Gingras (Ed.), Second language acquisition and foreign language teaching (pp. 27-50). Center for Applied Linguistics.

Schwartz, M., \& Verschik, A. (2013). Achieving success in family language policy: Parents, children and educators in interaction. In M. Schwartz \& A. Verschik (Eds.), Successful family language policy: Parents, children and educators in interaction (pp. 1-20). Springer.

Shohamy, E. (2006). Language policy: Hidden agendas and new approaches. Routledge.

Smith-Christmas, C. (2018). 'One as, Two Cas': Exploring the affective dimensions of family language policy. Multilingual, 37(2), 131-152.

Spolsky, B. (2004). Language policy. Cambridge University Press.

Spolsky, B. (2009). Language management. Cambridge University Press.

Tan, C. B. (2000). Socio-cultural diversities and identities. In K. H. Lee \& C. B. Tan (Eds.), The Chinese in Malaysia (pp. 37-70). Oxford University Press.

Tannenbaum, M. (2005). Viewing family relations through a linguistic lens: Symbolic aspects of language maintenance in immigrant families. Journal of Family Communication, 5, 229-252. 
Tannenbaum, M., \& Howie, P. (2002). The association between language maintenance and family relations: Chinese immigrant children in Australia. Journal of Multilingual and Multicultural Development, 23, 408-424.

Ting, S. H. (2018). Intergenerational transmission of the ethnic language: Hakka stops at Gen X. Grazer Linguistische Studien, 89, 63-88.

Vollmann, R., \& Soon, T. W. (2018). Multilingualism and language shift in a Malaysian Hakka family. Grazer Linguistische Studien, 89, 89-110.

Walsh, M. (2005). Indigenous languages of Southeast Australia, revitalisation and the role of education. Australian Review of Applied Linguistics, 28(2), 1-14.

Winter, J., \& Pauwels, A. (2005). Gender in the construction and transmission of ethnolinguistic identities and language maintenance in immigrant Australia. Australian Journal of Linguistics, 25(1), 153-168.

Wong, K. Z. H., \& Tan, Y. Y. (2017). Mandarinazition and the construction of Chinese ethnicity in Singapore. Chinese Language and Discourse, 8(1), 18-50.

Wong, V. (2017). The language medium policies: A study on the development of independent Chinese secondary schools (ICSS) in Malaysia. The Official Journal of the Centre for Civilisational Dialogue, 13, 32-53.

Wong-Fillmore, L. (1991). When learning a second language means losing the first. Early Childhood Research Quarterly, 6, 323-346.

Yen, C. H. (1993). Early Fukienese migration and social organisation in Singapore and Malaya before 1900. In P. T. Chang \& S. C. Liu (Eds.), Essays in Chinese maritime history (Vol. 5, pp. 679-740). Academic Sinica.

Zuckermann, G. (2020). Revivalistics. Oxford University Press. 